\title{
Entre Menchú y Borges : el tema de la identidad en el discurso del subcomandante Marcos
}

Kristine Vanden Berghe

\section{Résumé}

Entre Rigoberta Menchú et Borges. Le thème de l'identité dans le discours du Subcomandante Marcos.

Les chercheurs qui ont analysé les récits produits dans le cadre du soulèvement zapatiste au Chiapas ont souligné leur parenté avec la littérature de témoignage. Ils se sont probablement laissés guider par la ressemblance entre les contextes dans lesquels ces formes différentes de textes sont apparues et par l'objectif commun que toutes deux se proposent, c'est-à-dire de gagner l'adhésion de vastes secteurs de lecteurs. L'analyse me conduit à douter que le témoignage soit le principal modèle des récits zapatistes car plusieurs différences fondamentales les séparent des textes que l'on considère comme exemplaires de la littérature de témoignage. Elle découvre, au contraire, que les textes du Subcomandante Marcos reprennent le modèle de Cervantes, un Don Quichotte en Amérique, et mettent en circulation des présupposés littéraires et philosophiques de Borges dans un contexte politique et

idéologique entièrement distinct.

\section{Citer ce document / Cite this document :}

Vanden Berghe Kristine. Entre Menchú y Borges : el tema de la identidad en el discurso del subcomandante Marcos. In: América : Cahiers du CRICCAL, n³3, 2005. Les modèles et leur circulation en Amérique latine, v1. pp. 195-202;

doi : https://doi.org/10.3406/ameri.2005.1723

https://www.persee.fr/doc/ameri_0982-9237_2005_num_33_1_1723

Fichier pdf généré le 16/04/2018 


\section{Entre Menchú y Borges : el tema de la identidad en el discurso del Subcomandante Marcos.}

$N^{1}$ i el Ejército Zapatista de Liberación Nacional (EZLN) logró granjear tanta simpatía, fue entre otras razones porque sustituyó desde temprano las armas por las letras. Pendiente de su arsenal, el Subcomandante Marcos, el portavoz más conocido de la guerrilla, ha variado constantemente sus recursos discursivos, pues, numerosos comunicados de prensa suyos también incluyen relatos. Estos han llegado a independizarse de la palabra más llanamente política al salir reunidos en varios idiomas y en distintos volúmenes, los más completos siendo Relatos de el Viejo Antonio (1998) y Don Durito de la Lacandona (1999), ambos publicados por el Centro de Investigación y Análisis de Chiapas (CIACH). Sobre todo en los relatos sobre Durito, un escarabajo caballero andante, abundan los modelos literarios, a veces implícitos, otras veces abiertamente reivindicados : en ellos Marcos juega con el Quijote, incluye poemas de García Lorca y se refiere a Paul Éluard. A continuación me concentraré tan sólo en las huellas dejadas por dos modelos. El primero lo constituye el testimonio de Rigoberta Menchú (1983), sin duda el modelo más evidente. Pero también demostraré que los relatos de Marcos carecen de un rasgo que, sin embargo, es fundamental en el relato testimonial de Menchú. Precisamente, esta ausencia nos pone sobre la pista del segundo modelo, el cual es constituido por algunos presupuestos del pensamiento borgeano.

1 - Desde el punto de vista del género, los textos de Marcos han sido asociados con el modelo del testimonio de Menchú. En un artículo titulado "The Real Thing", el investigador de las literaturas centroamericanas John Beverley contestó de la manera siguiente a la pregunta sobre qué queda del "deseo llamado testimonio":

There are many ways one could answer this question, but it might be enough to say simply, understanding that it has functioned politically as something like what Lacan meant by the Real, Chiapas'.

Beverley toma prestado el término " deseo " de Fredric Jameson quien lo utilizó para referirse a los estudios culturales y describió el " deseo llamado estudios culturales" como el proyecto de constituir un bloque histórico que formara la base de una nueva disciplina. En cuanto a lo real, según Beverley,

1. John BeVerley, “The Real Thing” en: Gcorg M.Gugelberger, The Real Thing. Testimonial Discourse and Latin America, Durham and London: Duke University Press, 1996, p.282. 
en la acepción que le dio Lacan, significa lo que resiste de manera absoluta la simbolización ${ }^{1}$, lo que provoca un fuerte efecto de desfamiliarización ${ }^{2}$ o incluso lo que cancela la idea de que una forma particular de expresión cultural pueda constituir una representación adecuada de la realidad ${ }^{3}$. En otras palabras, Beverley opina que la rebelión de Chiapas ha causado un fuerte choque, produce enajenación y es difícilmente 'representable'. El artículo no profundiza en la relación entre la insurrección zapatista y el género testimonial, de manera que la referencia a Chiapas queda un poco en el aire. Es probable que la falta de perspectiva (el autor redactó su contribución en 1995) hiciera que la conexión aún no le resultara enteramente clara al autor. Pero el hecho de que la palabra Chiapas aparezca al final del artículo y que sea la última en una colección de textos dedicados al testimonio y otras formas de literatura afines, puede interpretarse como un reconocimiento implícito o una intuición por parte del autor y/o del compilador de que los textos del EZLN tienen cierta relación con el género pero también se desvian de él.

El hecho de que Beverley y otros ${ }^{4}$ hayan asociado los textos de Marcos con el género testimonial tiene que ver con determinados recursos discursivos pero se explicará sin duda también por las características propias del contexto. En cuanto a las coincidencias textuales, la lengua en la que se redacta una parte de dichos relatos revela un trabajo constante por parte de Marcos por desarticular e hibridizar el español mexicano mediante fusiones de la sintaxis del español con sintaxis desviantes, aparentemente indígenas ${ }^{5}$. Esta práctica, que es bastante frecuente en la novelística hispanoamericana y chiapaneca de tipo indigenista ${ }^{6}$ y que es fundamental en Menchú, resulta en un genuino "interlenguaje" y genera una "brecha metonímica " en la medida en que enfatiza la diferencia entre el español y las lenguas indigenas y que pide al lector hispanohablante que se comprometa activamente con la 'otra' cultura. Por otra parte, connota cierta torpeza expresiva que sirve para autentificar los textos de Marcos. Éstos convergen igualmente con el testimonio de Menchú

1. Ibid., p.266.

2. Ibid., p. 274.

3. Ibid., p. 273.

4. La asociación se cstablece, por cjemplo, en The Contemporary Mexican Chronicle. Theoretical Perspectives on The Liminal Genre cditado por Ignacio CORONA y Beth E. JORGENSEN (Albany: State University of New York Press, 2002).

5. Véase Kristinc VANDEN Berghe, "La alter/natividad en los Relatos de el Vicjo Antonio del Sub-comandante Marcos" en: Caravelle. Cahiers du monde hispanique et lusophone, $\mathrm{n}^{\circ} 78,2002$, p.197-209.

6. Ver Martin LIEnharD, La voz y su huella, Mćxico, Ediciones Casa Juan Pablos/Universidad de Cicncias y Artes de Chiapas, 2003.

7. Véasc Bill ASHCROFT e.a., The Empire writes back. Theory and Practice in Post-colonial Literaturas, London/New Cork, Routledge, 1989, p.66; Wolfgang RoTI," Sobrc la influcncia de las lenguas indigenas cn cl castcllano" en: Klaus ZimMERMAN (cd.), Lenguas en contacto en Hispanoamérica, Frankfurt am Main/Madrid, Vervucrt/lberoamerciana, 1995. 
ya que se trata de alegatos a favor de un cambio drástico e inmediato en las relaciones de fuerzas sociales. Pues, los relatos no sólo incluyen lo que Raymond Williams llamó aspectos "indicativos" que reflejan la realidad y describen la situación en Chiapas, en México y en el mundo globalizado, sino que también y sobre todo son "subjuntivos"1 porque quieren orientar al lector hacia cambios radicales, imposibles de realizar dentro del orden político y social establecido 2 .

Aparte de éstas y otras coincidencias textuales, creo que han sido sobre todo los aspectos más contextuales los que han inducido a ver los textos de Marcos en función de cierta literatura testimonial. El que Marcos escriba desde el área geográfica centroamericana por ejemplo, región donde el testimonio había sido durante cierto tiempo el modelo literario por excelencia, es uno de ellos ${ }^{3}$. Luego, también el que la colectividad por la que habla sea el pueblo maya, despierta ecos de los escritos de Menchú. A esto se añade el hecho de que Marcos escriba en calidad de portavoz de un movimiento indígena, una tarea intermediaria que supone un yo-narrador que surge como una extensión de su colectividad, tarea tradicionalmente también asociada con el testimonio centroamericano. Sin embargo, es precisamente aquí, en la imagen que Marcos se crea de sí mismo en calidad de intermediario y portavoz - de hecho prefiere decir que es un traductor-, donde sus textos se desvian de los textos de Menchú.

2- A raíz sobre todo de los reproches dirigidos a Menchú después de los análisis críticos de David Stoll ${ }^{4}$, se ha argumentado a su favor que una testiga

1. Raymond WILLIAMS, “Forms of fiction in 1848 " en: Francis BARKER e.a. (cds.), Literature, Politics and Theory, London, Mcthucn, 1986, p. 12.

2. Este aspecto, por lo demás, emparenta los relatos de Marcos igualmente con textos literarios que no son narraciones testimoniales. En la medida en que se propone presionar a favor de la democratización de México y transformarlo en un genuino estado multicultural y pluriétnico, y salvadas las grandes diferencias de ćpoca, cstilo y géncro, Marcos se inscribc en una tradición y actualiza una práctica de varios fundadores de las modernas naciones latinoamericanas, como Rómulo Gallegos, Andrés Bcllo o José Martí quicnes cscribicron novelas y poesia a fin de construir y dar una forma peculiar a sus respectivas naciones (vćasc, por ejemplo, Doris SOMMER, “Irresistible romance: the foundational fictions of Latin America " cn: Homi K. ВНАвHA (cd.), Nation and Narration, London/New York, Routledgc, 1995, p.73). Como cllos, cl Subcomandante da cucrpo a un proyecto politico por medio de una ficción nacional fundacional $\mathrm{c}$ intenta implementar csta ficción mediante proyectos legisladores y campañas militares. También continúa cl trabajo de los poetas en las repúblicas centroamericanas en los años sesenta y sctenta cuya pocsia quiso tener una relevancia social y politica inmediata (John BEVERLEY y Marc ZIMMERMAN, Literature and Politics in the Central American Revolutions, Austin, Univcrsity of Texas Press, 1990). Pcsc a los diagnósticos contrarios (Hermann Herlingaus y Monica WALTER, “ ¿Modemidad pcrifćrica” versus 'proyecto de la modernidad'? Experiencias epistemológicas para una reformulación de lo "pos'moderno desde Amćrica Latina " en : Hermann Herlinghaus y Monika Walter, Posmodernidad en la periferia : enfoques latinoamericanos de la nueva teoria cultural, Bcrlín, Langer, 1994, 11-47; Viccntc LECUNA, La ciudad letrada en el planeta electrónico. La situación actual del intelectual latino-americano. Madrid: Plicgos, 1999), su práctica como escritor podria ser un indicio de que en determinados circulos en México y en América Latina en gencral sigue viva la fe en cl poder de la literatura cuando se trata de dar fucrza a demandas políticas y de cambiar las maneras de concebir la sociedad.

3. John Beverley y Marc Zimmerman, op.cit.

4. David StolL, Rigoberta Menchu and the Story of All Poor Guatemalans, Boulder, Westvicw Press, 1999. 
indígena como Menchú padece inevitablemente de cierta esquizofrenia debida a su deseo de captar la atención de una audiencia externa, lo cual supone una ladinización de su lengua y de su manera de representar ${ }^{1}$. Por otra parte, esta " esquizofrenia " no impide que los textos de Menchú tengan una coherencia interna en la medida en que Menchú se presenta siempre y sistemáticamente como indigena, subalterna y como un sujeto coherente y único. Su autorretrato, en este sentido, es tributario del pensamiento moderno.

En este aspecto, el autorretrato de Marcos presenta rasgos que se desvian sustancialmente. Primero, el mestizo Marcos se crea un autorretrato ambiguo y contradictorio con respecto a su identidad étnica ya que a veces se presenta como maya, a veces como ladino. Un ejemplo basta para ilustrarlo. El sistema pronominal empleado en diversos textos escritos por el Subcomandante confirma que éste ha llegado a formar parte de la comunidad indigena y que, por lo tanto, es representativo de ella y puede hablar en calidad de testimoniante suyo. La cita siguiente es ejemplo de esto: "Nos encontramos con un país dispuesto a escuchar a los que nadie escuchó antes, dispuesto a dar vida a quienes siempre murieron en el olvido, dispuesto a hablar a quienes siempre fueron ignorados, dispuesto a incluirnos en el 'nosotros' " (comunicado del 25 de agosto de 1995 en EZLN2, p.434). En este texto, Marcos expresa su satisfacción por el hecho de que la nación mexicana haya acabado por estar dispuesta a tratar a los indígenas como personas de pleno derecho. Llama la atención que escriba " incluirnos" y no "incluir a los indígenas". Mediante el pronombre objeto directo se presenta como uno de los indígenas.

Pero la manera en la que Marcos emplea el sistema pronominal carece de coherencia: en varios comunicados alternan las formas del " yo "/ " ellos" y del " nosotros. La declaración arriba citada da cuenta de ello en la medida en que Marcos, en combinación con la primera persona del plural, " incluirnos ", también utiliza la tercera persona " murieron" $y$ " fueron ignorados". Es una contradicción que sigue produciéndose en varios textos donde la primera y la tercera persona se alternan sin que haya una distribución lógica entre ambas ${ }^{2}$.

Uno tiene la impresión de que las contradicciones no son deslices accidentales sino que son introducidas por Marcos con miras a hacerse un autorretrato en el que predominan los trazos desestabilizadores y poco nítidos ; la índole proteica de su autorretrato puede relacionarse con las críticas que se

1. Véase Ilse LoGie, " La verdad de los hechos: el testimonialismo de Rigoberta Menchú " en: Aleph, $n^{\circ} 16$, cncro de 2002, p. $19-26$.

2. En otros muchos comunicados Marcos incluso se retrata sistemática y abiertamente como mestizo o como diferente frente a los indigenas. Asi sucle destacar su nariz, excepcionalmente grande y nada maya. Otro indicio de su origen y cultura mestiza es su cstilo. Aunque emplec numerosas formas que parcen tomadas prestadas de las lenguas indigenas, maneja un cstilo propio que hace que a menudo sea posible distinguir desde el íncipit los textos firmados por él, de los comunicados atribuidos a la comandancia indigena del EZLN. La ironia, la intertextualidad, y un amplio conocimiento de la cultura occidental - desde cl Quijote hasta Brigitte Bardot - son algunos ingredientes básicos de estos textos. De haber querido verdaderamente que el público lo viera como un indigena, Marcos habria copiado sin duda de manera más sistemática cl cstilo de los comunicados atribuidos a la comandancia indigena. 
le dirigen por ser un outsider y no formar parte de la comunidad indígena. De esta manera las contradicciones funcionan para desarmar a sus adversarios que insisten en su identidad mestiza y en su bagaje cultural occidental para negarle el derecho de representar a los indigenas. Al crearse una identidad múltiple, Marcos intenta escapar a las categorias identitarias que esencializan y que permiten atacarle. Al mismo tiempo, la distancia creada entre sí mismo y los indígenas también puede entenderse a partir de la premisa de que una identificación con los indígenas no es necesaria si se trata de realizar un proyecto común en calidad de aliados dignos. Además, parece sugerir que una identificación sólo en parte es posible y que él, como no indígena, nunca podrá formar totalmente parte de los pueblos mayas.

Por otro lado, cabe observar que el autorretrato de Marcos no sólo adquiere rasgos proteicos cuando el tema es su pertenencia étnica sino que la pluriformidad constituye el rasgo básico de su identidad asi como del retrato de sus personajes literarios. El escarabajo caballero andante Don Durito de la Lacandona no tarda en asignarse a sí mismo un escudero, un Sancho Panza, el SupMarcos. Como ocurre a menudo en los relatos de Marcos, el Subcomandante, autor y narrador, se retrata a si mismo como personaje e interlocutor. En el personaje que le corresponde destaca un rasgo particular: frente a Don Durito de la Lacandona, Sancho Panza/SupMarcos ocupa una posición subordinada y dependiente. De hecho, Marcos incluso intensifica la posición de subordinación del personaje. En calidad de escudero, Marcos debería servir a su amo; sin embargo y por el contrario, le ruega constantemente a Durito que le ayude. A una de estas súplicas, Durito contesta: "Yo, señor mío, soy un caballero andante, y los caballeros andantes no podemos dejar de socorrer al necesitado, por más narizón y delincuente que sea el desvalido en cuestión " (Don Durito de la Lacandona p.53, comunicado de mayo de 1995).

Pero llama la atención que Durito no sólo se presente como Don Quijote y Marcos no salga únicamente 'disfrazado' de Sancho Panza. Conforme los textos se publican, las identidades se multiplican y se borran, con lo cual Marcos también acaba por ofrecer imágenes literarias contradictorias. Con ocasión de la apertura del Primer Encuentro Intercontinental por la Humanidad y contra el Neoliberalismo Marcos se dirigió a su público con las palabras siguientes:

Buenas tardes a todos. Hemos llegado un poco tarde y les pedimos que nos disculpen, pero es que nos hemos topado con unos gigantes multinacionales que nos querían impedir llegar. El mayor Moisés nos dice que son molinos de viento; el comandante Tacho dice que son helicópteros. Yo les digo que no les crean: eran gigantes'.

1. Citado cn Manuel VázQuez Montalbàn, Marcos: El señor de los espejos. Madrid: Aguilar, 1999, s. p. 
En esta cita, Marcos se asigna a sí mismo el rol de Don Quijote - el que imagina ver a los gigantes - en vez del de Sancho Panza. En otro momento se convierte en boca de Durito en "mi querido Guatson" (Don Durito de la Lacandona p. 75, comunicado del 17 de julio de 1995; comunicado de septiembre/octubre de 1995) o "Whatson Sup " (ibid., p. 18, comunicado del 11 de marzo de 1995). Esto haría pensar que Durito se presentaría como Sherlock Holmes. Sin embargo, una vez más los papeles se mezclan ya que Durito no es Sherlock Holmes sino que éste es un antiguo alumno del escarabajo quien se sorprende del hecho de que "Jolms" haya llegado a ser un personaje literario famoso.

Cabe señalar que el cuestionamiento de la noción del sujeto concierne tanto al sujeto politico (los zapatistas y Marcos) como al sujeto literario (el autor). Aparte de 'Holms', otro escritor que se hizo famoso gracias a Durito es Bertolt Brecht. Durito resulta ser el autor verdadero de la obra de Brecht a quien dejó, por simpatía, el honor de firmar sus textos: "Bueno debo advertirte que Bertolt se limitaba a transcribir lo que yo le iba dictando. Algo muy parecido a lo que tú haces ahora. Pero ese detalle no lo hagas público" (Don Durito de la Lacandona, p. 137, comunicado del 5 de julio de 1996). En honor a Brecht, Durito está dispuesto a hacer como si los dos hubieran escrito juntos el texto en cuestión. Su título: “Ponencia conjunta del Bertolt y el Durito ". El lugar y la fecha: “ Berlín-San Cristóbal, 1949-1996”. Marcos le advierte en cierto momento a Durito: "Creo que te están confundiendo los tiempos y las novelas" (ibid., p. 33, comunicado del 4 de abril de 1995). A esta crítica, Durito opone repetidamente su propia visión lamentando que Marcos no la pueda compartir ya que no conoce la teoría de Umberto Eco sobre la 'opera aperta' (ibid., p. 91, comunicado del 14 de enero de 1996). Además de ser un adepto de dicha teoría, Durito está convencido de que la naturaleza imita al arte (ibid. p. 33, comunicado del 4 de abril de 1995; ibid., p.67, comunicado de junio de 1995; véase también ponencia del 31 de julio de 1996 en EZLN3, p. 329) y de que no se completa la obra abierta hasta que el lector no se convierta en coautor (ibid., p. 92, comunicado del 14 de enero de 1996), afirmaciones que confirman cada una a su manera la función prioritaria de los signos en la guerrilla zapatista.

La confusión entre personajes y voces en los textos de Marcos induce a ver a los personajes en relación con la índole inestable y cambiante de la identidad individual. En los relatos de Marcos esta confusión no sólo parece apuntar hacia su problema personal en materia de etnicidad $y$ de representatividad sino que mediante ella Marcos muestra que se adhiere a la crítica posmoderna de la idea tradicional del sujeto homogéneo y propone una crítica de la noción moderna del sujeto que preside el relato testimonial de Menchú.

3- Por lo que precede no sorprenderá que, en cierto momento, Marcos haya empezado a mencionar el nombre de Jorge Luis Borges (comunicado del 28 de mayo de 1994 en EZLN1, p. 239; comunicado del 16 de enero de 
1995 en EZLN2, p. 200; comunicado del 14 de marzo de 1995 en EZLN2, p. 274; Discurso de Clausura al Encuentro Nacional en Defensa del Patrimonio Cultural de agosto de 1996 en Subcomandante Marcos 2000, p. 160 y 172) ${ }^{1}$ y esto a pesar de la insalvabilidad de las diferencias ideológicas entre ambos hombres. Estas alusiones no son meras menciones puntuales sino que constituyen un intertexto estructural. En efecto, la presencia de Borges puede leerse como una clave interpretativa mediante la cual Marcos llama la atención sobre las coincidencias que existen entre el modelo borgeano y su propia obra. Quien lea los relatos a partir de esta clave no tendrá mayores dificultades en descubrir las intersecciones entre los textos de Borges y los relatos de Marcos. De la misma manera que el escritor argentino, el guerrillero se crea un personaje detrás del cual se disimula; con él comparte un gusto por lo clandestino y la mistificación; sus autorretratos muestran que, de la misma manera que Borges, considera que el escritor es un humilde redactor y como él practica la escritura como una lucha contra los géneros establecidos, como reivindicación de la parodia y transgresión del canon. Sobre todo, como Borges cuestiona la noción de sujeto desde una multiplicidad de ángulos.

Además, las alusiones a Borges constituyen comentarios casi programáticos con los que Marcos cuestiona el reclamo de validación empírica que preside, por ejemplo, al proyecto testimonialista de Menchú. Asimismo parece decir que no es natural la relación que solemos establecer entre discurso y realidad, que sus textos, por consiguiente, no son referencias miméticas de la realidad sino que crean otra realidad autónoma. Este cuestionamiento anula los presupuestos del testimonio de Menchú ya que erige una relación menos transparente con la realidad. El que Marcos incluya en sus comunicados políticos fragmentos literarios con personajes ficticios aún agranda esta distancia porque esta opción implica que disminuye el reclamo de representatividad y confirma la dificultad de transparencia del discurso, de transposición fiel entre la realidad y el texto. Al revés, señala el carácter mediatizado de la relación entre ambos así como la indole subjetiva de la experiencia de la realidad. Esto es incompatible con la asunción básica que preside el contrato de lectura del testimonio que reclama la existencia de una correspondencia fáctica entre discurso y referente.

Como hipótesis explicativa de tal desviación propongo que la relacionemos con el rasgo básico en el autorretrato del EZLN, guerrilla que se perfila sistemáticamente como un movimiento democrático. Los zapatistas,

1. En una ocasión antcrior (Kristinc VANDEN BERGHE, “Don Quijote y el pasamontañas. Intertextualidad y autoria en los textos del EZLN" en Rita DE MAESENEER (cd.), Convergencias e interferencias. Escribir desde los borders, Valencia, Excultura, 2001) lleguć a una conclusión distinta porque no hay ninguna referencia a Borges en el libro Don Durito de la Lacandona, libro al que limité mi análisis cntonces. 
en efecto, casi siempre han negado poseer la verdad y proclaman su confianza en la solución que consiste en que se confrontan una pluralidad de visiones ofrecidas por el inagotable caleidoscopio a través del cual cada uno desde sus propias circunstancias percibe su propia realidad.

Kristine VANDEN BERGHE, FUNDP Namur/FUSL Bruselas 